\title{
LA CONSTRUCCIÓN DEL ARQUETIPO NORTEAMERICANO. LA IMAGEN CINEMATOGRÁFICA Y TELEVISIVA DE ABRAHAM LINCOLN EN LOS ESTADOS UNIDOS
}

\section{THE CONSTRUCTION OF THE AMERICAN ARCHETYPE. THE CINEMATOGRAPHIC AND TELEVISION IMAGE OF ABRAHAM LINCOLN IN THE UNITED STATES}

\author{
Juan Agustín Mancebo Roca \\ Universidad de Castilla-La Mancha
}

\section{RESUMEN}

El legado histórico de Abraham Lincoln lo ha convertido probablemente en el presidente más importante de los Estados Unidos. Su defensa de la Unión, la abolición de la esclavitud y la Guerra Civil, lo han transformado en el líder esencial para comprender la América contemporánea. Por ello, Lincoln ha sido un referente en la historia del cine norteamericano. Desde las filmaciones tempranas hasta la actualidad, el decimosexto presidente ha constituido un arquetipo representacional asociado a los periodos históricos en los que su figura ha sido reconstruida, vinculada mayoritariamente a tiempos de crisis en los que se refrendaba su carácter mediador y su inteligencia política como modelos de afirmación norteamericana. Lincoln, que había sido capaz de unir y reconciliar a la nación en el periodo más crítico de su joven cronología, se convirtió en el modelo de construcción del mito norteamericano, cuya mención iluminó los periodos oscuros de la Depresión y la Segunda Guerra Mundial. Cuando el país se convirtió en la potencia hegemónica, su figura evolucionó como memoria visual y referente ante los abusos de poder y a las políticas manipuladoras.

Palabras clave: cine histórico; Abraham Lincoln; Estados Unidos; memoria; cultura popular.

\section{ABSTRACT}

The historical legacy of Abraham Lincoln has made him probably the most important U.S. president. His support of the Union, the abolition of slavery and the Civil War have made him the central figure of contemporary American understanding. That is why Lincoln has been a landmark in American film history. From early filming to the present day, the 16th President has been a representational archetype of the historical periods in which his figure has been reconstructed. A figure mainly linked to periods of crisis in which his mediating character and political intelligence were endorsed as models of American affirmation. Lincoln, who had been able to unite and reconcile the nation in the most critical period of its young chronology, became the model for the construction of the American myth. His mention shed light on the dark periods of depression and the Second World War. When his country became the world's hegemonic power, his figure was transmuted into visual memory as a reference in the face of abuses of power and manipulative policies.

Keywords: Historic cinema; Abraham Lincoln; United States; memory, popular culture. 


\section{INTRODUCCIÓN}

Abraham Lincoln (1809-1865) ha sido el presidente de los Estados Unidos que ha tenido un mayor número de registros en la historia del cine. Estudios recientes cifran su presencia en más de trescientas producciones cinematográficas y televisivas a lo largo del siglo XX y que ha continuado en los inicios del siglo XXI. Pero su relevancia mediática no responde solo a una cuestión exponencial sino también a su trascendencia cinematográfica. Realizadores de la talla de David Wark Griffith, John Ford o Steven Spielberg han sintetizado la fascinación por la magnitud humana, política e histórica del mandatario esencial para comprender el renacimiento y la actualidad de los Estados Unidos modernos.

Es sintomático que su rol cinematográfico y televisivo haya cumplido criterios didácticos y su figura se haya instrumentalizado para trasladar mensajes políticos en periodos críticos. De este modo, su representación se ha metamorfoseado en distintos arquetipos como ha señalado Brian J. Snee: el del gran corazón en El nacimiento de una nación; el salvador de la Unión en Abraham Lincoln; el plebeyo en El joven Lincoln; el primer americano en Lincoln en Illinois; Abraham el Honesto en la serie basada en la obra de Sandburg, el anti-Lincoln en la miniserie Raices de Gloria y el gran emancipador en la monumental superproducción Lincoln de Steven Spielberg.

La imagen cinematográfica y televisiva del presidente ha ido cambiando, adecuándose a los relatos políticos y sociales que quería trasladar el país a través de la industria del entretenimiento. De este modo, las primeras filmaciones lo reconocían como un mandatario condescendiente que evolucionará a un personaje más complejo en la primera lectura que hizo Grifftih y, posteriormente en la segunda lectura del director de Kentucky, así como los modelos de Ford y Cromwell, que compondrán el arquetipo representacional del mandatario en un momento de descomposición de los valores identitarios norteamericanos por las amenazas externas.

Con el comienzo de la Guerra Fría, el advenimiento televisivo y la irrupción de un nuevo modelo de político, la figura de Lincoln entró en crisis. También lo hizo su legado, sometido a un revisionismo que incidía en los puntos más oscuros -que los hubo- de su abolicionismo. De hecho, aparecieron estudios críticos en los que la lectura del personaje se concebía como la de cualquier hombre, con sus fortalezas, sus dudas y sus debilidades. Finalmente, el descrédito de ciertas administraciones norteamericanas ha llevado a nuevos estudios de Lincoln que, con los ataques del 11 de septiembre, ha tenido un nuevo revival cinematográfico y televisivo. Este modelo, que volvía a cerrar filas en torno a la figura del presidente norteamericano, probablemente haya compuesto la imagen canónica de Lincoln en el primer cuarto del siglo XXI.

En cualquier caso, la instrumentalización de la imagen mediática de Abraham Lincoln sirve como referente para poder contextualizar la historia reciente de Norteamérica y el cine realizado en los Estados Unidos y que se ha proyectado al mundo como la potencia hegemónica cultural del siglo XX.

\section{MARCO TEÓRICO, ANTECEDENTES Y METODOLOGÍA}

Este artículo estudia la construcción de la figura de Abraham Lincoln en el cine y la televisión norteamericana y cómo ha sido instrumentalizada estableciendo paralelismos entre la representación del arquetipo cinematográfico y su lectura histórica a través de la pequeña y la gran pantalla. Lincoln aparecería en las primeras filmaciones de la historia del cine y fue uno de los personajes centrales de la película El nacimiento de una nación que cambió el paradigma histórico y representacional del cine. A partir de ese momento, se irá construyendo un patrón sobre su figura y su legado que iría metamorfoseándose respecto a los cambios históricos del país. Desde los inicios del cine hasta finales de los cuarenta, la imagen del presidente se vinculará a la bondad, la templanza y la justicia, que se reforzarían hasta la mitificación coincidiendo con la entrada de los Estados Unidos en la Segunda Guerra Mundial.

El discurso centrado en su personalidad y sus logros políticos se resquebrajará cuando el país inicie un proceso de reconocimiento de los derechos de las minorías en el que se pondrá en duda su legado. A partir de los setenta, la revisión de su figura ha estado determinada por 
la espectacularización mediática, que focalizó sus intereses en políticos recientes, así como por el desencanto con las distintas administraciones políticas que pusieron en entredicho su dimensión histórica. Esta crisis de su modelo representacional se ha extendido con los ataques del 11-S y la pérdida de libertades a favor de un mayor control de la seguridad. Lincoln ha emergido de nuevo con la revisión de Spielberg, que recuperaba su figura como el gran icono de la historia de los Estados Unidos, incidiendo en el interés de la industria en un personaje esencial de la historia norteamericana.

Para la elaboración del trabajo se han tomado como referente las películas canónicas sobre la figura del decimosexto presidente, mayoritariamente realizadas por directores reconocidos, aunque se han consultado obras pretéritas con menor relevancia que habían establecido una política representacional en el momento en el que fueron realizadas. En cuanto a la televisión, se han utilizado las miniseries basadas en los libros homónimos del historiador Carl Sandburg y del novelista Gore Vidal, así como películas específicas para el medio.

Dentro de los modelos cinematográficos y de las relaciones entre historia y cine, el trabajo se apoya en los estudios hemerográficos de Anne-Marie Paquet-Deyris (2019) que abordaba la construcción icónica de la figura presidencial desde La cabaña del tío Tom (Edwin S. Porter, 1903) hasta Abraham Lincoln, El joven Lincoln y Lincoln en Illinois; Antonio Sánchez Escalonilla y Araceli Rodríguez Mateos (2014) revisan la épica de su figura a partir del gobierno de Obama y su reflejo en el Hollywood contemporáneo; Edward Goyeneche-Gómez (2012) estudia los soportes audiovisuales y su transcripción histórica y Mark E. Benbow (2010) analiza la instrumentalización política que Woodrow Wilson hizo de El nacimiento de una nación. En cuanto a los análisis fílmicos específicos se ha partido de los estudios de Santiago Mariani (2018) y José Díaz-Cuesta (2012) que han tratado los elementos históricos y la representación del modelo presidencial respectivamente en el Lincoln de Spielberg; Eduardo Morettin (2011) ha estudiado las relaciones entre historia y cine en El joven Lincoln; Ruth Gutiérrez Delgado (2011) ha realizado dos estudios sobre la icónica película de Ford. En el primero estudiaba la influencia del libro The True Story of a Great Life (1888) de W. H. Herdorn y de J. J. Weik, mientras en el segundo examinaba el perfil épico de la figura presidencial. Es esencial, a este respecto, el estudio de Melvyn Stokes (2011) que consideraba pormenorizadamente la figura del presidente en sus adaptaciones cinematográficas y su contexto cultural.

Así mismo, se han tomado como referentes bibliográficos los trabajos de Brian J. Snee (2016) que investiga la fascinación que ha ejercido la figura del decimosexto presidente en el cine a través de El nacimiento de una nación, Abraham Lincoln, El joven Lincoln, Lincoln en Illinois, y los Lincolns de Sandburg y de Vidal, así como el estudio de Melvyn Stokes (2007) sobre El nacimiento de una nación que indagaba en la cuestión racial y política del filme. Del mismo modo, el trabajo de Ian Scott ha servido para clarificar la escena política y su representación en Hollywood. Se han utilizado los libros de Gore Vidal (2007 y 2011), sus ensayos -en los que se refiere episódicamente a la figura presidencial y a la política norteamericana- y su novela Lincoln, completado con los trabajos monográficos de Gallagher (2009), Reinhard (2009) y Marzal (1998) entre otros.

En cuanto a los referentes históricos se ha partido del trabajo de De Francisco y Blackburn (2013) que recoge la relación entre el presidente Lincoln y Karl Marx que incluye sus discursos, artículos sobre el devenir de la guerra y el problema de la esclavitud, el intercambio epistolar entre ambos y una cronología de los acontecimientos históricos determinantes; Carmen de la Guardia Herrero (2008) estudia la relación histórica del Lincoln de Griffith. Finalmente, el trabajo se ha completado con la biografía de Lincoln a cargo de Isaac Montero (2004) y se han atendido a las diferentes ediciones de los discursos de la carrera política del presidente norteamericano.

\section{DE LOS PRIMEROS AÑOS A EL NACIMIENTO DE UNA NACIÓN}

Abraham Lincoln fue una figura recurrente en los inicios del cine norteamericano. El pionero Edwin S. Porter (1870-1941) utilizó su imagen en dos producciones de la Edison Film Company: The Martyred Presidents (1901) a raíz del asesinato del presidente William McKinley (1843-1901) y La cabaña del tío Tom (Uncle Tom's Cabin, 1903) en la que Lincoln liberaba a un esclavo. Entre 
1908 y 1915 apareció en treinta y nueve películas, siendo su primera biografía The Life of Abraham Lincoln (1908), una obra de diez minutos producida por Essanay de la que no existen copias. Las producciones primitivas en las que aparecía el presidente incidían en su condescendencia (Reinhard, 2009: 8) como reflejaba la producción de la Vitagraph The Reprieve; an Episode in the life of Abraham Lincoln (Van Dike Brooke, 1908) en la que Lincoln perdonaba la vida a un centinela que se había quedado dormido. En este caso la historia se filtraba en la pantalla: "como presidente de la Unión tenía el privilegio de la clemencia. Y aunque era un hombre enérgico, le costaba firmar sentencias de muerte" (Montero, 2004: 167).

La producción When Lincoln Paid (Francis Ford, 1913), escrita por William Clifford (1877-1841) resumiría el espíritu de estas primeras aproximaciones. Francis Ford (1881-1953) hermano y mentor de John Ford, interpretaría a Lincoln en siete películas entre 1912 y 1915 y en When Lincoln Paid se retrotraía a los inicios del joven político. El argumento narraba la ayuda que Lincoln recibía de una mujer tras una tormenta. Años después, durante la guerra, intercedería por ella para salvar la vida de un espía sudista, hijo de un general de la Confederación que, previamente, había ajusticiado al hijo de su benefactora.

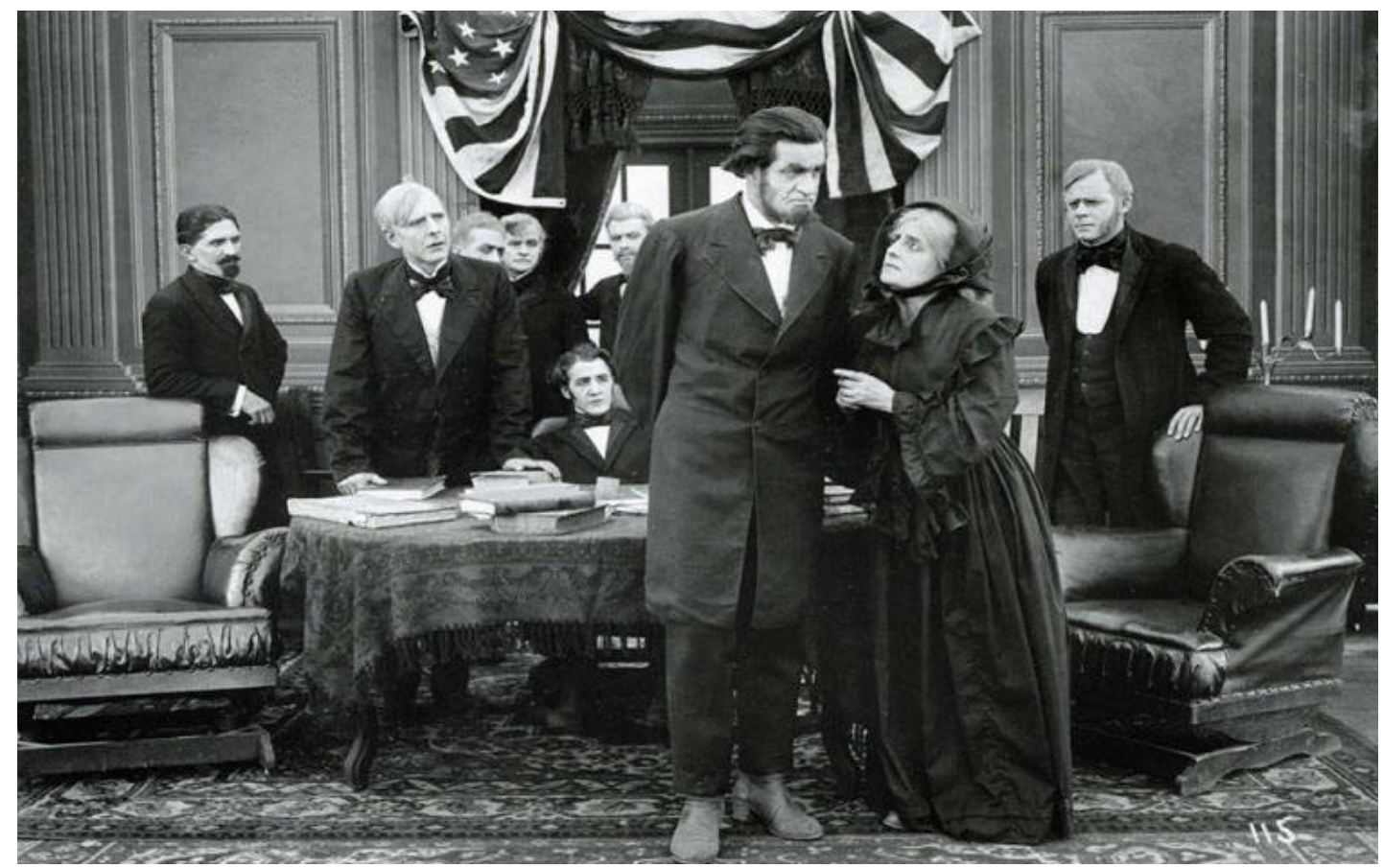

Figura 1. Abraham Lincoln [Francis Ford] en When Lincoln paid, Francis Ford. 1913.

Pero quien fundamentó el primer modelo cinematográfico de Lincoln fue David Wark Griffith (1875-1948) que se aproximó a su figura en dos películas: El nacimiento de una nación (The Birth of a Nation, 1915) y Abraham Lincoln (1930) -Griffith, por otra parte, lo había interpretado como actor en Chicago en la obra de William Haworth The Ensing (1898)-. Junto con Intolerancia (Intolerance, 1916), El nacimiento de una nación fue su propuesta más ambiciosa, siendo ambas películas fundamentales para el devenir de la historia del cine. El nacimiento de una nación se distinguió por los avances de la narrativa audiovisual que inauguraría el modo de representación institucional, término acuñado por Noël Burch en 1968 sobre las nuevas convenciones que adoptaría el lenguaje cinematográfico para que los filmes tuvieran coherencia interna y, desde esa perspectiva "puede decirse que el cine, hasta hoy mismo, solo ha conocido dos épocas: la anterior a Griffith y la posterior a él" (Gimferrer, 2000: 11).

La película abordaba la guerra de Secesión y el periodo de Reconstrucción en el que Lincoln [Joseph Henabery] apoyaba la emancipación de los afroamericanos y acababa con la tradición esclavista del Sur. Por otra parte, el final de la Guerra de Secesión suponía la destrucción de un modelo social decimonónico que sería restaurado en la ficción cinematográfica por el Ku Klux Klan. El Lincoln que presentaba el filme era un personaje admirable puesto que más allá de las presiones que recibió en ese momento, defendió los 
derechos de los confederados intentando reunificar el país tras la guerra. Pese a ser un convencido defensor de la causa sudista, Griffith consideraba que si Lincoln no hubiera sido asesinado la Reconstrucción y específicamente la Reconstrucción "radical” no hubiera tenido lugar (Stokes, 2011: 207).

El nacimiento de una nación, por otra parte, era la adaptación de dos de las novelas de la denominada trilogía de la reconstrucción de Thomas Dixon (1864-1946), The Clansman (1905) y, en menor medida, The Leopard's Spots (1902), ficciones literarias que se contemplaban como hechos históricos rigurosos. The Clansman había sido anteriormente rodada por William Haddock (1877-1969) para la Kinemacolor Company (1912) pero un proceso químico destruyó la película una vez filmada.

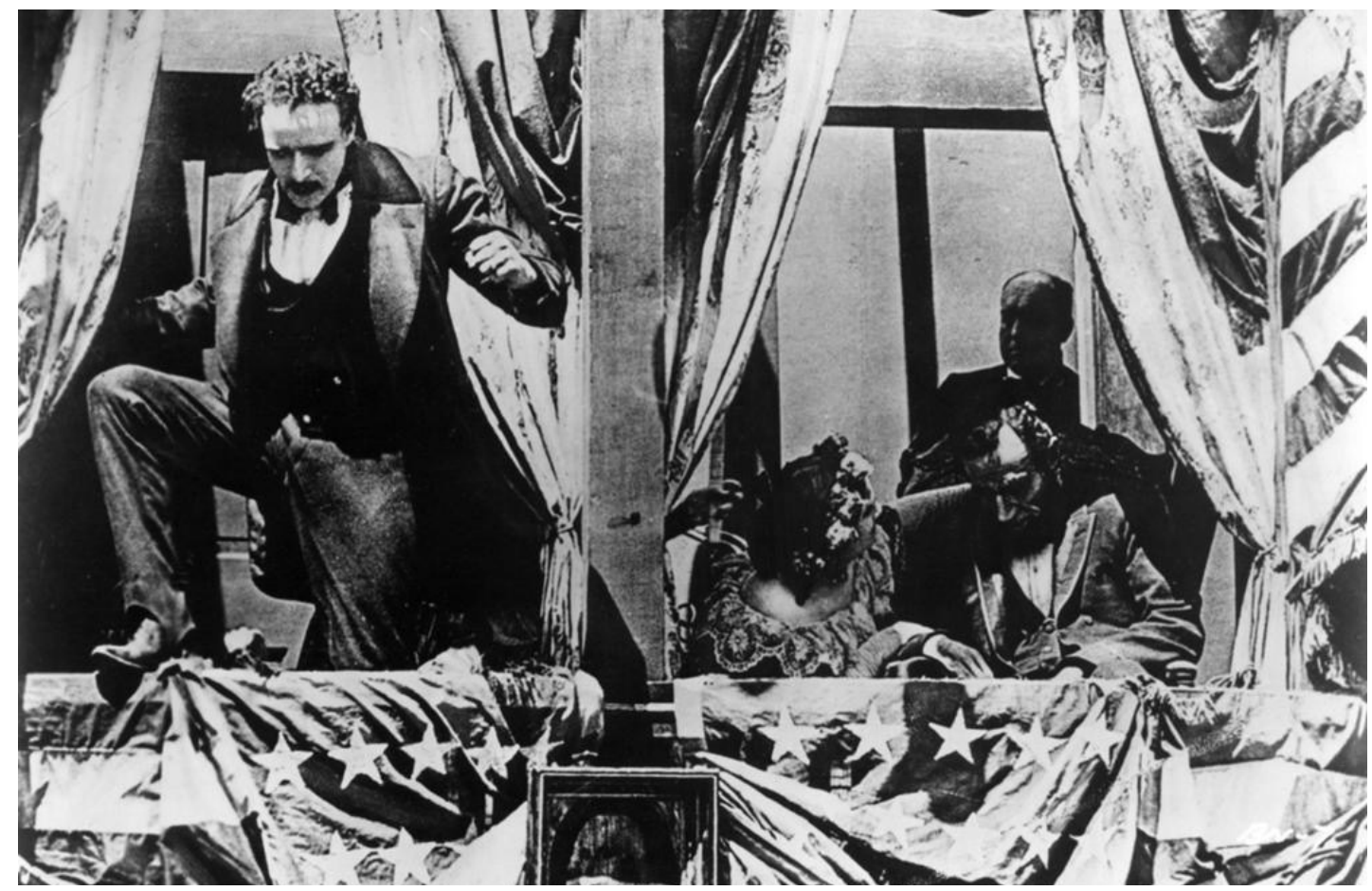

Figura 2. John Wilkes Booth [Raoul Walsh] salta del palco tras asesinar a Lincoln [Josep Henareby] en presencia de su mujer en el Teatro Ford de Washington en El nacimiento de una nación, David W. Griffith. 1915.

La atención por la verosimilitud histórica de El nacimiento de una nación se manifestaba en escenas como la del asesinato de Lincoln en el Teatro Ford a manos del actor John Wilkes Booth (1838-1865) -interpretado por el futuro realizador Raoul Walsh (1887-1980)- y que se atenía a una rigurosa reconstrucción del suceso (Marzal, 1998: 128-9). Esta escena fue una de las referencias publicitarias de la filmación y serviría de modelo para casi todas las producciones fílmicas posteriores exceptuando la de Spielberg, que se negó a incluirla puesto que consideraba que estaba sobreexplotada por el cine.

Pero Griffith, al igual que en las novelas de Dixon, hizo una lectura tendenciosa de la historia. Introdujo como personaje esencial al congresista Thaddeus Stevens (1792-1868), un abolicionista radical que propuso confiscar las propiedades de los sureños, que sus delegados no tuvieran representación en las cámaras y que se tratara a los Estados rebeldes como territorios conquistados (Stokes, 2007: 20). Stevens, que estaba casado con la mulata Lydia Smith, se transformaba en el filme en Austin Stoneman [Ralph Lewis] y su mujer en Lydia Brown [Mary Alden] que configurarían dos personalidades dañinas que celebrarían el asesinato de Lincoln. En otras interpretaciones la figura de Stevens representaría lo contrario, ya que fue un político esencial para la defensa de los derechos y libertades de los afroamericanos en los Estados Unidos.

El nacimiento de una nación supuso uno de los primeros acontecimientos sociológicos del cine. De hecho, su génesis y rodaje se referencia en Good Morning Babilonia (Paolo y Vittorio Taviani, 1987) y Asi empezó Hollywood (Nickelodeon, Peter Bogdanovich, 1976) como la obra que ejemplificaba la transición de los modelos artesanales al estándar hegemónico 
de la producción cinematográfica. Por otra parte, la controversia estuvo presente desde los inicios de la filmación. El racismo de Griffith hizo que muchos actores de color se retiraran del proyecto, siendo figurantes blancos maquillados los que interpretarían sus papeles. Pese a que la National Association for the Advancement of Colored People -N.A.A.C.P.- pidió expresamente la retirada del filme por la imagen tendenciosa que ofrecía de las personas de color, solo consiguieron que el metraje fuera recortado de 1.544 a 1.375 planos para evitar las escenas más controvertidas. Así mismo, se eliminó el polémico epílogo sobre la deportación a África de todos los afroamericanos del país que Griffith, que trasladaba del argumento de Dixon -y que estuvo en los planes de Lincoln-, proponía como solución al problema racial.

El 8 de febrero de 1915 se realizó la premiere en el Auditorium Clune de Los Ángeles con el título El hombre del clan y se estrenó el 3 de marzo en el Teatro Liberty de Nueva York, proemio de los altercados contra la población de color en Boston y Filadelfia donde hubo víctimas mortales. Otras ciudades cancelaron el filme para evitar disturbios. Por su parte el presidente Woodrow Wilson (1856-1924), que estaba muy interesado en el cine, instrumentalizó políticamente la imagen que la película ofrecía de los afroamericanos. Wilson comprendió las posibilidades propagandísticas del medio en un periodo en el que se comenzaban a permeabilizar los paralelismos entre Washington y Hollywood. Wilson vio el filme en un pase especial en la Casa Blanca en febrero de 1915 y, tras la proyección exclamó: "Es como escribir la historia con candilejas. Lo único que lamento es que es demasiado terrible", aunque parece ser que la segunda parte de la frase era un añadido para atenuar su marcado racismo (Bembow, 2010, p. 509). En los intertítulos aparecía una frase del propio Wilson extraída de sus libros de historia: "Los hombres blancos fueron provocados por un mero instinto de supervivencia hasta que finalmente surgió un gran Ku Klux Klan, un verdadero imperio del Sur, para proteger al territorio sureño". El presidente, constituido como modelo de espectador (Goyeneche-Gómez, 2012: 404) aprovechó la distribución del filme para ganarse el voto del Sur en las elecciones de 1916 ya que tenía un escaso margen de intención de voto sobre el candidato republicano Charles Evans Hughes (1862-1948), si bien es cierto que, tras la polémica inicial, se desligó del mensaje racial descalificando públicamente la película.

Durante el mandato de Wilson, se reactivaron las políticas segregacionistas que apenas se habían modificado desde el final de la guerra de secesión. El nacimiento de una nación supuso un renovado interés por la figura del Ku Klux Klan, que languidecía en el Sur desde el último tercio del siglo XIX, convirtiéndose en un instrumento de propaganda para captar nuevos adeptos hasta los años treinta. Tras la Primera Guerra Mundial, hubo un retorno a los valores de los WASP, blancos, anglosajones y protestantes, así como una gran desconfianza a todo aquello que no representara los valores fundacionales estadounidenses. El Ku Klux Klan se convertiría en garante de las costumbres norteamericanas sembrando el terror ante cualquier amenaza a su ortodoxia, un renacimiento del antiguo Klan de la Reconstrucción, que tuvo su cénit con la manifestación de fuerza de cincuenta mil simpatizantes de su causa en Washington el 8 de agosto de 1925.

Griffith se autoexculpó del contenido racista del filme con un folleto titulado The Rise and Fall of Free Speech in America (1916) y, además, como contrapunto a la polémica película, rodaría la citada Intolerancia incidiendo en la reconciliación de los pueblos. Pese a su carácter poco edificante, la película fue un majestuoso espectáculo que inauguró el cine de propaganda política y la crítica cinematográfica. La figura de Lincoln y El nacimiento de una nación se convirtieron en parte de la memoria visual de los Estados Unidos en un periodo en el que se estaban revisando y reconstruyendo los mitos norteamericanos. Lincoln, como garante de la reconciliación, tenía "una caracterización humana y misericordiosa de un presidente que utiliza su poder de manera compasiva" (Mariani, 2018: 181) y Griffith lo transformaría en la gran figura mesiánica de los Estados Unidos, contribuyendo a consolidar la visión de un personaje reflexivo y que sufría por sus decisiones siendo capaz de adoptar posturas impopulares para beneficiar al colectivo. Esa memoria se combinaba con la historia del cine ya que en El nacimiento de una nación trabajaron entre otros Erich von Stroheim (1885-1957), John Ford (1894-1973), Woody S. Van Dyke (1889-1943), Jack Conway (1887-1952) y el citado Walsh, que unos años después escribirían la historia dorada de Hollywood. 


\section{ABRAHAM LINCOLN, REFERENTE CINEMATOGRÁFICO EN TIEMPOS DE CRISIS}

La segunda etapa cinematográfica sobre la figura de Lincoln abarcó las décadas de los veinte, treinta y cuarenta, en la que la cinematografía norteamericana construyó un personaje mitificado que reivindicaba su inteligencia política y el valor de la palabra para unificar un país que estaba sumido en la crisis derivada del crack bursátil del veintinueve y, posteriormente, por la Segunda Guerra Mundial. Si El nacimiento de una nación apuntaló la popularidad de Lincoln en el imaginario nacional, su notoriedad se amplificó con la publicación del primer volumen de la obra canónica Abraham Lincoln: the Prairie Years (1926) de Carl Sandburg (18781967).

El recurso cinematográfico de Lincoln aparecía en el filme Tierra de oportunidades (The Land of Opportunity, 1920) de la Selznick Pictures Corporation que fue protagonizada y dirigida por Ralph Ince (1887-1937). La película era un encargo del Comité de Americanización para ser proyectada a los emigrantes que llegaban al país con el fin de transmitir los valores norteamericanos a través de la biografía del presidente.

Pero será la tríada de filmes Abraham Lincoln (Abraham Lincoln) de Griffith, El joven Lincoln (Young Mr. Lincoln, John Ford, 1939) y Lincoln en Illinois (Abe Lincoln in Illinois, John Crownwell, 1940) los que configurarían "una tradición hagiográfica y melodramática" (Paquet-Deyris, 2016: 12) sobre la figura del presidente constituyendo el modelo representacional cinematográfico que iría desde la Depresión a la Segunda Guerra Mundial y que marcaría gran parte de los arquetipos de la representación presidencial hasta las revisiones de finales del siglo XX.

Pese a que solo habían pasado tres lustros entre una película y otra, la distancia entre El nacimiento de una nación y Abraham Lincoln parece mucho mayor. Producida por United Artist, fue el primer filme sonoro del director y uno de los mejores ejemplos del que se denomina su periodo de decadencia. El filme recalcaba la figura del presidente al servicio de una imagen cinematográfica institucionalizada en una obra más cercana al documental que a una propuesta personal a través de un discurso hagiográfico que hacía una lectura triunfalista y escasamente crítica. Abraham Lincoln relataba los hechos más destacados de su biografía política, especialmente los debates con Stephen Douglas (1813-1861) y su relación con Ulysses S. Grant (1822-1885), centrándose en su vida personal, sus vínculos con la comunidad, su relación con Ann Rutledge (1813-1835) [Una Merkel] y su matrimonio con Mary Todd (1818-1882) [Kay Hammond], la presidencia y su asesinato. Griffith, que siempre consideró las fuentes gráficas del cine como un elemento superior del discurso histórico, utilizó también fuentes bibliográficas para componer la película "el Pictorial History of the Civil War de Harper, el libro de Mathew Brady Civil War Photographs; Confederate and the Union Veterans-Eyewittness on Location y otras fuentes similares" (Guardia Herrero, 2008: 39). Esa información la trasladó, fiel a su estilo, en la elección del mobiliario, a las escenas de batalla y a la minuciosa reconstrucción de su asesinato.

Abraham Lincoln adolecía de cierto esquematismo argumental, aunque señalaba rasgos esenciales del presidente como su acromegalia, su vigor físico y su peculiar lenguaje corporal que serían constantes en otras producciones. En el filme, Griffith pretendía trazar la historia de un hombre, pero terminaba deificándolo cuando establecía paralelismos entre su figura y la de Jesucristo, en la que uno de sus interlocutores le replicaba el "hágase tu voluntad". Otra de las características de la filmación es que no hacía referencia al tema de la esclavitud. En el debate con Stephen Douglas, Lincoln [Walter Huston] mantenía: "no consentiremos la esclavitud en ningún Estado. No permitiremos la secesión de ningún Estado. Ante todo, y por encima de todo, debemos mantener la Unión", es decir, hacía hincapié en la unidad por encima de cualquier consideración de la Unión como entidad perpetua que resaltaría posteriormente en su discurso de investidura.

Al final del filme, el tañido de las campanas visualizaba la cabaña de troncos en la que nació Lincoln en Hodgenville, Kentucky -declarado lugar de interés nacional (Snee, 2016: 4)disuelta en la imagen presidencial del escultor Daniel Chester French (1850-1931) en el conjunto arquitectónico del Lincoln Memorial de Washington de Henry Bacon (1866-1924) iniciado en 1914 y concluido en 1922. Esa síntesis entre el modesto nacimiento y la dimensión de su legado combinada con las notas de The Battle Hymm of the Republic -compuesta al comienzo de la Guerra de Secesión-, reforzaban su iconicidad como metáfora del sueño americano. 


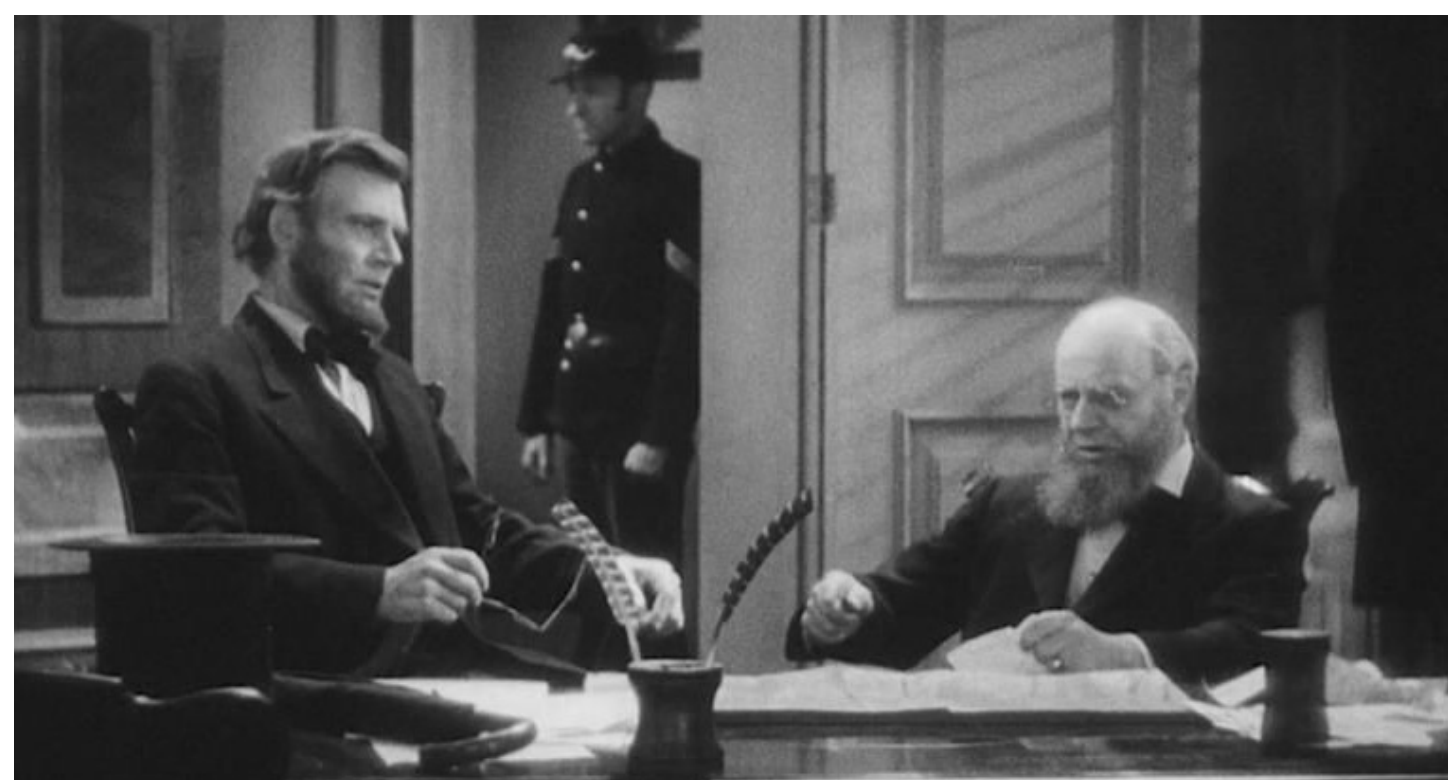

Figura 3. Lincoln [Walter Huston] y Edward Stanton [Oscar Apfel] en Abraham Lincoln, David W. Griffith. 1930.

Estrenada el 25 de octubre de 1930 en Nueva York, la película tuvo buena crítica y el New York Times "resaltó la labor memorable de Walter Huston [...] así como el excelente guion del premio Pulitzer, Stephen Vincent Benet" (Guardia Herrero, 2008: 39). Por el contrario, fue un tremendo fracaso de público y apenas estuvo una semana en cartel. El productor Joseph $\mathrm{M}$. Schenk (1876-1961), desencantado con el fiasco económico de la misma no volvería a trabajar más con Griffith (Marzal, 1998, p. 203).

Abraham Lincoln apareció en un contexto histórico y social complejo debido a la pérdida de fe los norteamericanos por el colapso financiero de 1929 y a las funestas implicaciones que tuvo para la nación. Por ello, ante una producción cultural escapista basada en héroes populares y superhéroes, esta película constituyó una propuesta de retorno a los valores primigenios que fundamentaron la consolidación del proyecto nacional, intentando reinstaurar la confianza perdida a partir del modelo presidencial que, si bien no cuajó entre el público, constituiría el primer emblema serio de la representación del presidente en su cinematografía estableciendo la memoria como espacio preeminente para los estadounidenses (Scott, 2011: 26).

La segunda película de la tríada llegaría nueve años después de la mano de John Ford, que había sido ayudante de Griffith y actor en El nacimiento de una nación. Como hemos señalado, su hermano había realizado la citada When Lincoln Paid y Ford lo había incluido a Lincoln en un papel secundario como impulsor del transcontinental en su primera gran película El caballo de hierro (The Iron Horse, 1924). El asesinato del presidente y el controvertido juicio de los conspiradores había constituido el argumento de Prisionero del odio (Prisoner of Shark Island, 1936) película que resultaba "conflictiva en términos de representación histórica" (McBridge, 2004: 286). El director de origen irlandés admiraba profundamente a Lincoln por sus implicaciones históricas y la defensa de los valores norteamericanos. Pese a que se consideraba que fue una imposición de Darryl F. Zanuk (1902-1979), para Ford fue un proyecto cinematográfico relevante, aunque la sobreexplotación de la figura del presidente le hiciera concebir dudas para desarrollarlo.

Pese a que existen referencias a la película de Griffith, Ford focalizó la historia en su juventud, concretamente en el periodo de formación anterior a su ingreso en el Senado, cuando era un abogado idealista que pretendía hacer política. De hecho, la política aparece de soslayo, haciendo una llamada que reforzaba su carácter sencillo y humilde. Mientras que el Lincoln de Griffith planteaba una pétrea idea de la salvaguarda de la Unión, el de Ford distinguía entre lo que está bien y lo que está mal que determinaría una política futura basada en la justicia.

La reconstrucción realizada por John Ford era la de un joven impreciso y melancólico -que se enfatizaba con la mención a los decesos de su hermana, su madre y de su primer amor, Ann Rutledge [Pauline Moore]- y que, a partir de unos tímidos inicios, va adquiriendo 
seguridad conforme avanza la película en la que resaltaba poderosamente el lenguaje corporal de Henry Fonda. Ford decía que cuando Henry Fonda se movía caminaba el cine. De hecho, el cuerpo desgarbado de Lincoln ocupaba al principio posiciones inverosímiles que reflejaban su carácter independiente y que se irían moderando conforme avanzaba la historia hasta dominar completamente la escena. Esa exageración de la corporalidad de Lincoln la reseñaría la crítica señalando el parecido entre Lincoln y el conde Orlok de Nosferatu: una sinfonia del horror (Nosferatu, eine Symphonie des Grauens, F. W. Murnau, 1922), un velado homenaje de Ford al director alemán que apuntalaba el icono visual de Lincoln hasta la actualidad, permeabilizado en producciones mainstream como Abrahm Lincoln: cazador de vampiros (Abraham Lincoln: Vampire Hunter, Timur Bekmanbetov, 2012).

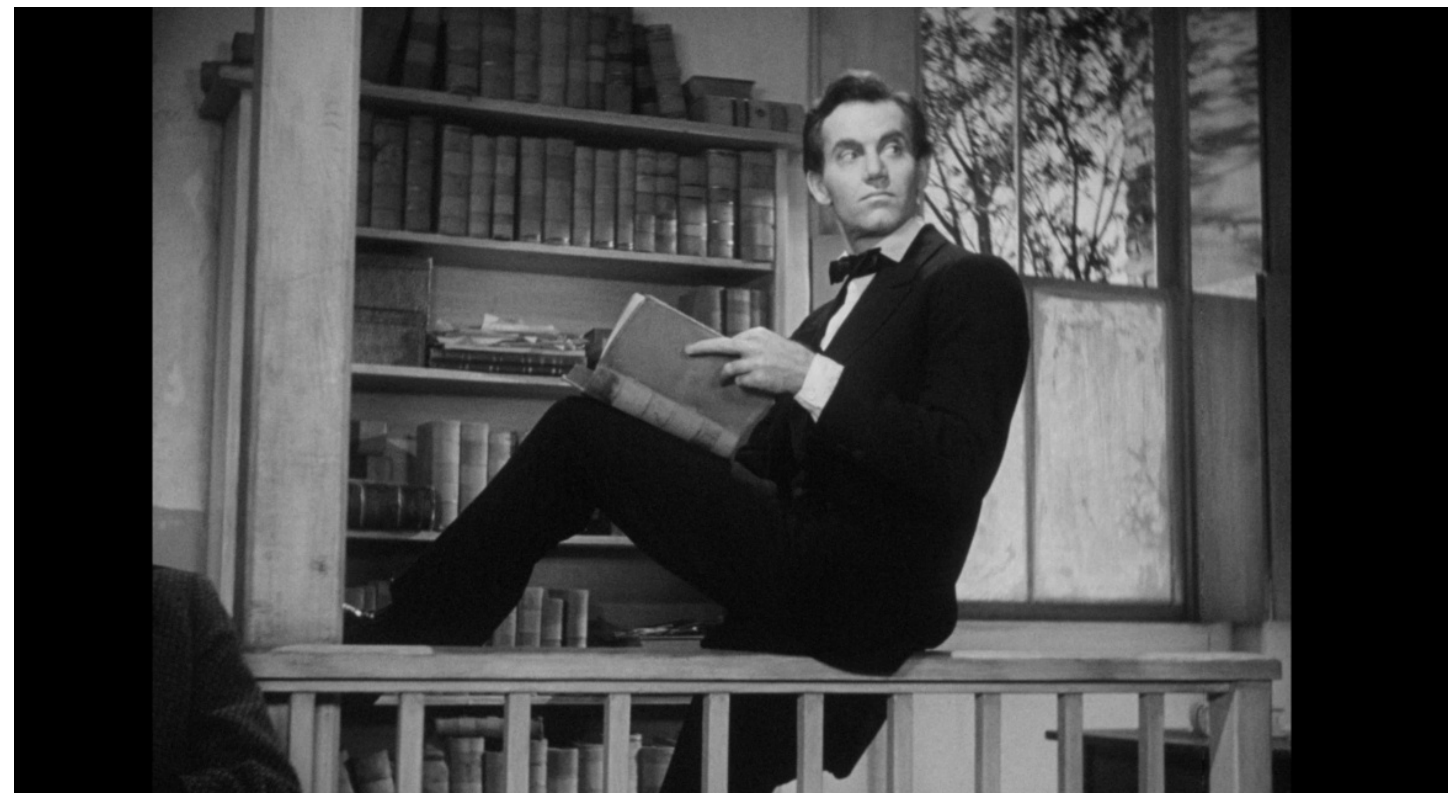

Figura 4. El cuerpo que domina la escena. Abraham Lincoln [Henry Fonda] en El joven Lincoln. 1939.

La historia de El joven Lincoln comenzaba en 1832 en New Salem, un pueblo del condado de Menard, Illinois, localidad fronteriza en la expansión del país hacia en Oeste y centro de mercancías del tráfico comercial por el río (Montero, 2004: 65). Desde el inicio, el filme incidía en el carácter autodidacta y las dificultades de la formación del futuro presidente: "nunca asistí a la escuela -escribió en 1859- la poca instrucción que tengo la adquirí aguijoneado por la necesidad" (Lincoln, 2013: 64). Del mismo modo, subrayaba la relación de Lincoln con la ley cuando intercambia víveres por libros, los Commentaries on the Laws of England (1765-1769) de William Blackstone, un conjunto de leyes vigente en Inglaterra y base de la Constitución de los Estados Unidos (Morettin, 2011, p. 21) y que además le servirán como instrumento para sus estudios de derecho (Montero, 2004: 79). El filme visibilizaba a los veteranos de la Guerra de Independencia (1775-1783) y a los de la Guerra angloestadounidense de 1812 para mantener el vínculo entre los héroes americanos y el hombre que Lincoln llegaría a ser.

En cuanto a la documentación histórica hay conexiones explícitas con la biografía de W. H. Herndon y J. J. Weik, Abraham Lincoln, The True Story of a Great Life (1888). Herdon (1818-1891) fue compañero de bufete de Lincoln en Springfield desde 1844 hasta 1861 y su libro cuenta con "material privilegiado para fundamentar el grado de historicidad del filme" (Gutiérrez, 2011). El juicio que recreaba la película estaba basado en uno real de 1857 en el que Lincoln utilizó $E l$ almanaque del viejo granjero para resolver un caso contra Jack Armstrong (Gallagher, 2009: 230). En la película observamos cómo la humildad del principio se convierte en una velada ambición en la que el futuro presidente utilizará todas las estratagemas posibles para lograr su objetivo.

La secuencia final proyectaba a un Lincoln vencedor que reinstauraba la unión familiar injustamente quebrada por la acusación de los hermanos Clay y que se podía extrapolar al Estado en su conjunto (Gutiérrez Delgado, 2011) ensalzando los valores de la comunidad a través de la justicia que se proyectaba al exterior. Esta salida no estaba dirigida hacia los ciudadanos de Springfield, sino que iba más allá de la pantalla, focalizándose hacia 
el espectador, lo que fortalecía uno de los imaginarios contemporáneos recurrentes: el paralelismo entre la imagen y la política. Como en el caso de Abraham Lincoln, la película no hacía mención a la esclavitud, aparte de una referencia de pasada, y tampoco aparecían actores afroamericanos, lo que obedecía al condicionamiento racial de la época: "cuando los negros no interpretaban más que a botones se los suprimía en las películas proyectadas en el Sur; a tenor de las películas de Hollywood en los años treinta, no se podía sospechar que los negros existían en Estados Unidos" (Gallagher, 2009: 224).

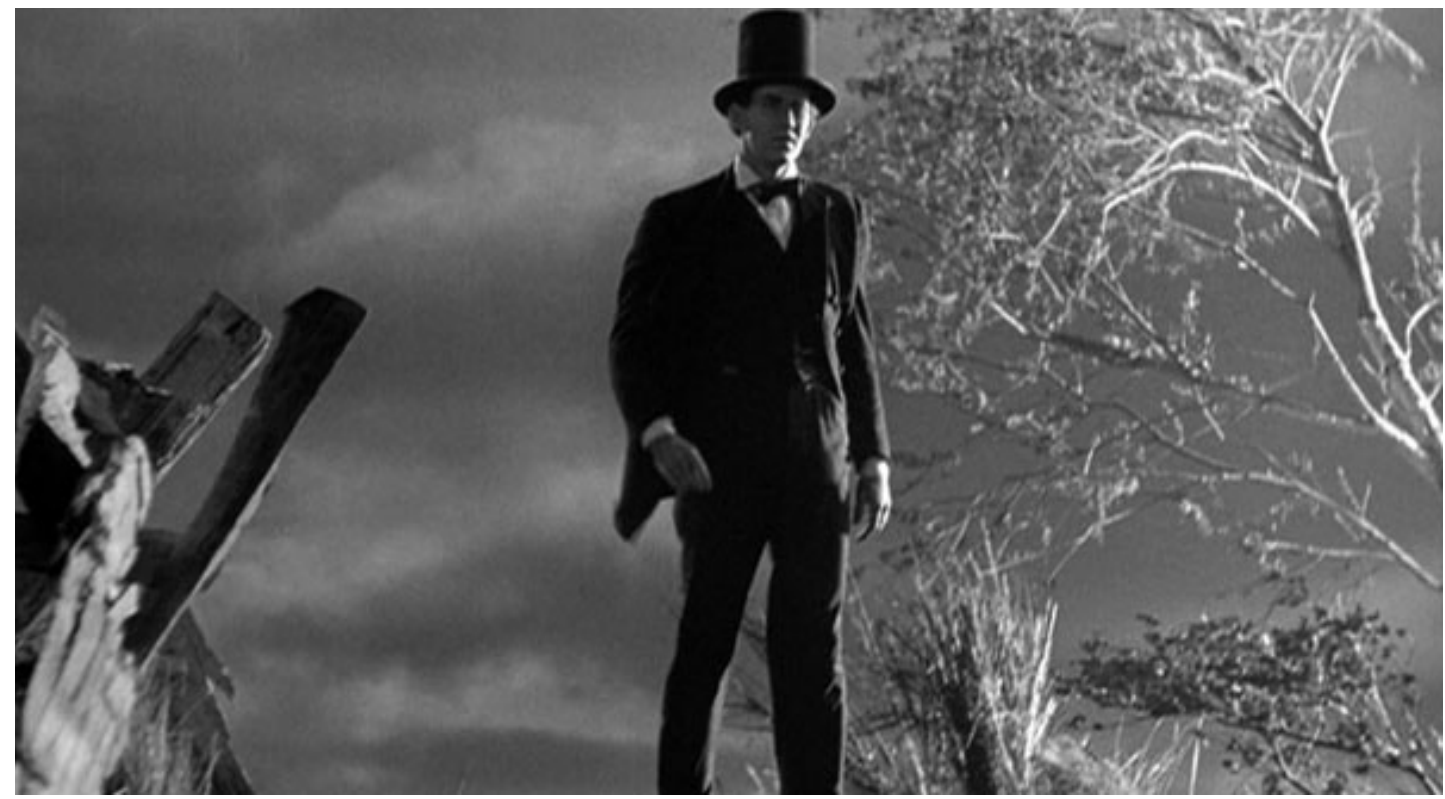

Figura 5. Abraham Lincoln [Henry Fonda] luchando contra las inclemencias de tiempo como proyección de futuro en El joven Lincoln, John Ford. 1939.

La conclusión de El joven Lincoln recurría a los tópicos que reafirmaban su proyección en el imaginario norteamericano. Las notas de The Battle Hymm of the Republic y la referencia icónica de la bandera ensalzaba a un "héroe en formación, y la imagen cristalizada en escultura en el lugar evocativo de su memoria [...] refuerza y amplía la división cívica presente en el memorial [Lincoln]" (Morettin, 2011: 20). En este sentido, se podría afirmar que El joven Lincoln era una película propagandística puesto que Ford recurría a la leyenda y al mito para reaccionar ante el auge de los totalitarismos en Europa, idealizando su cultura y afirmando su superioridad ante la destrucción del viejo continente (Álvarez Junco, 2017: 117). Abraham Lincoln representaría el refugio simbólico y el espíritu patriótico de los ideales de la nación. Como mantenía Serguéi Eisenstein, la película hacía referencia a la concordia en una época lúgubre en la que la guerra reinstauraba la búsqueda de las armonías perdidas (Eisenstein, 2017: 40).

Rodada en vísperas de que los Estados Unidos entraran en guerra, John Ford anticipaba el conflicto reclamando un espíritu de unidad para cerrar filas frente al enemigo. De hecho, como muchos directores y actores de Hollywood, Ford trabajaría como documentalista para el ejército norteamericano durante la Segunda Guerra Mundial recuperando el espíritu del presidente norteamericano en el documental La batalla de Midway (The battle of Midway, 1942), en el que hacía referencia al soldado Will Keaney nacido en Springfield -aunque en este caso de Ohio-, equiparando su figura con la de todos aquellos que lucharon contra los japoneses. Recientemente, se ha citado el rodaje del documental de Ford en el filme Midway (Ronald Emmerich, 2019).

El fervor por la figura de Lincoln se concretó en Lincoln en Illinois, adaptación cinematográfica de pieza teatral de la Plawright's Company de Robert Sherwood (18961955) que ganaría el premio Pulitzer y tendría más de cuatrocientas representaciones en Nueva York. El propio Sherwood escribió la adaptación para la RKO dirigida por el siempre solvente John Cromwell (1887-1979). La película componía un retrato de Lincoln [Raymond Massey] en su época en Springfield (Illinois) desde 1831 hasta que fue elegido presidente en 1861, siendo la filmación de la época que prestaba más atención a la 
verosimilitud histórica. Uno de los leitmotifs del joven Lincoln eran el ansia de saber y el aprendizaje a través de libros y los maestros que le ayudan desinteresadamente. Del mismo modo, reseñaba su inteligencia y el uso racional de la fuerza para ser aceptado y querido por sus rivales a los que convertía en amigos, una metáfora del espíritu de unidad tras la guerra.

Como en las películas anteriores, se incidía en el hecho de la muerte de su madre y la experiencia traumática de Ann Rutledge [Mary Howard] así como en el reconocimiento de la comunidad cuando el partido Whig -futuro partido republicano- lo escogió como candidato para la Asamblea. La elección en 1835 en el que se le reconoce como Abe el Honesto, coincidiría con el periodo de expansión del país hacia Tejas y California. Su victoria, por otra parte, quedaba empañada por el complejo momento personal tras la muerte de Ann en el que se vislumbra la fatalidad de la vida personal del futuro presidente. La filmación establecía una crítica al sistema y a los políticos cuando Lincoln abandona la actividad pública decepcionado con la falta de preparación y la carencia de escrúpulos de algunos políticos.

La segunda parte se estructuraba a partir de la relación con Mary Todd [Ruth Gordon], la ambiciosa guía que espoleará al pusilánime Abraham. Pese a la oposición familiar y las dudas de Lincoln, se convirtieron en un sólido matrimonio que anticiparía rasgos futuros: Mary Todd sabía que Lincoln será en el futuro presidente y conocerá su destino trágico cuando una de sus criadas haga un despreocupado comentario mencionando que Lincoln nunca saldría vivo de Washington.

La filmación hace una aproximación a la figura presidencial estableciendo paralelismos con el desarrollo y la historia del país. La cuestión racial adquiere mayor protagonismo a partir de dos hechos históricos: el primero, la referencia a los abolicionistas liderados por John Brown para acabar con la esclavitud en Kansas que fueron reprimidos por el entonces militar de la Unión y futuro general de la Confederación Robert E. Lee (Montero, 2004: 123); la segunda se focalizaba en los discursos con Stephen Douglas [Gene Lockhart] que configuran el centro de la filmación. A diferencia de su contrincante, que abogaba por la equidistancia ante el problema de la esclavitud, la actitud de Lincoln es la de un firme abolicionismo que proclamaba que todos los hombres habían sido creados iguales y que la indiferencia ante el problema de la esclavitud generaba un sufrimiento innecesario.

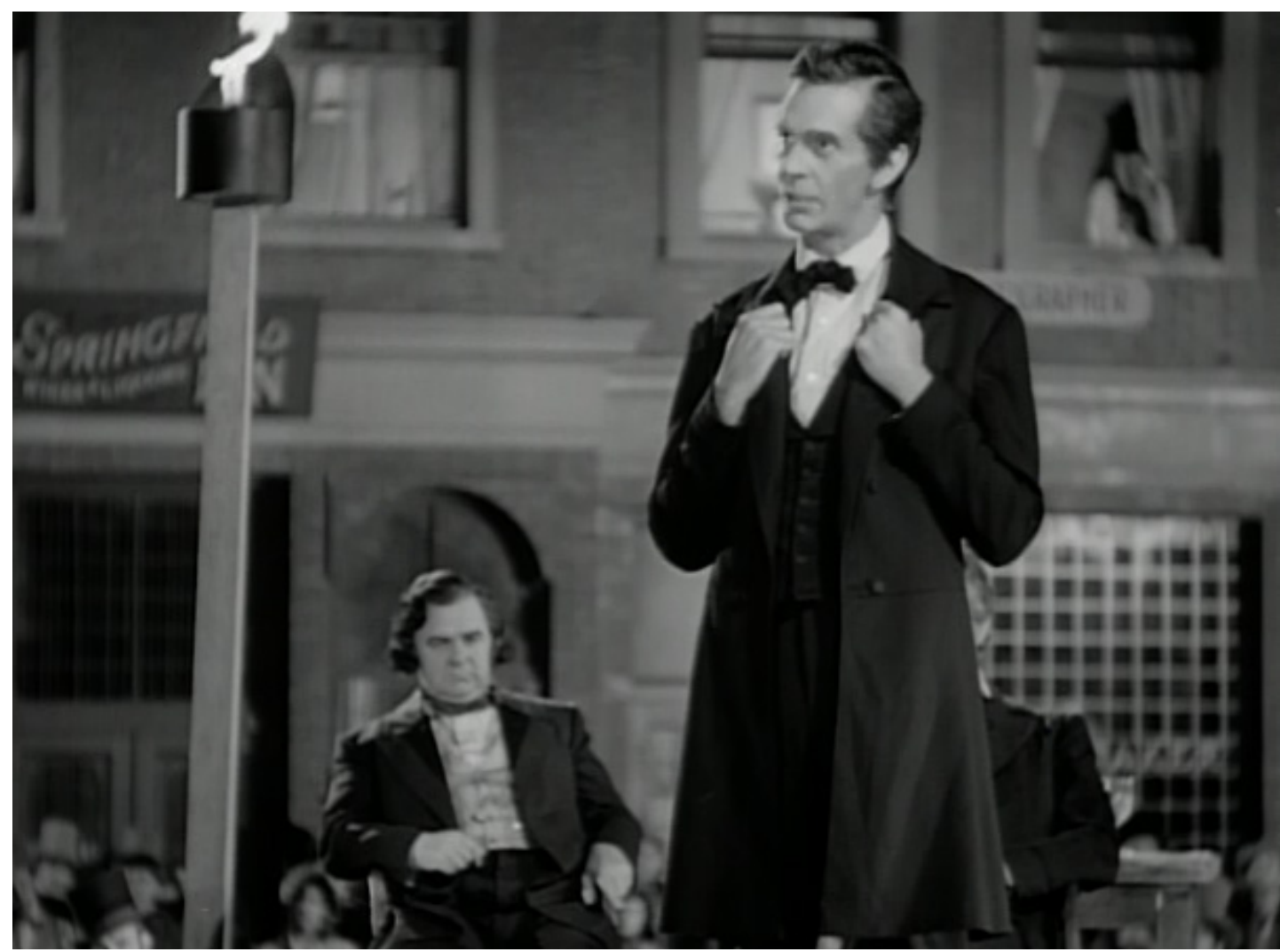

Figura 6. Lincoln [Raymond Massey] debatiendo con Stephen Douglas [Gene Lockhart] en Abe Lincoln en Illimois, John Cromwell. 1940. 
Al igual que en otros filmes se particulariza la preocupación del presidente y de Mary Todd- y su relación con los medios de comunicación a través de la fotografía, en la que destacaba su carácter familiar cuando se convierte en senador por Illinois. Otro detalle relevante era trasladar la idea de que Lincoln escuchaba al pueblo. El ya elegido presidente señalaba antes de su partida a la Casa Blanca que se había dejado la barba ya que una niña le escribió que le conferiría dignidad, hecho real basado en una carta que le escribió Grace Bedell de once años el día 15 de octubre de 1860 (Lincoln, 2015: 20).

Pese a ser una película que celebraba el mito del decimosexto presidente hay algunos elementos que la distinguen. Por ejemplo, se apuntaba al presunto ateísmo de Lincoln, que aparecerá en revisiones posteriores, ya que ciertos sectores conservadores lo acusaron de no pertenecer a ninguna iglesia y ser políticamente un radical. En este caso, la película trae a colación los hechos acaecidos en la campaña para el congreso de la Unión en 1846 en la que su oponente, el pastor metodista Peter Cartwright (1785-1872) le atacó personalmente ${ }^{1}$ También señalaba las amenazas que recibió nada más ganar las elecciones. Pese a ello, antes de partir a Washington, permitiría que sus correligionarios se le acercaran enfatizando su comunión con el pueblo que le ha visto crecer personal y políticamente. La filmación recreaba el destino al que se debe entregar cuando parte hacia la Casa Blanca en el ferrocarril. Su partida, metafóricamente, supone el principio en el que arrancaría la novela de Gore Vidal y la miniserie de Lamont Johnson.

El joven Lincoln y Lincoln en Illinois ejemplificaron el refuerzo cinematográfico de su figura en la memoria colectiva norteamericana como sucedía en el resto de las artes. En 1937, su imagen fue esculpida por Gutzon Borglum (1867-1941) en el Monte Rushmore (Dakota del Sur) junto a George Washington, Thomas Jefferson y Theodore Roosevelt. En 1939, Jefferson Smith [James Stewart] conversaba con la escultura del presidente en el Lincoln Memorial para afirmar los valores constitucionales en Caballero sin espada (Mr. Smith Goes to Washington, Frank Capra, 1939). Ese año, Carl Sandburg publicó cuatro volúmenes de su monumental biografía Abraham Lincoln: the war years. La sobreexposición de Lincoln establecía paralelismos entre su figura y la de Franklin D. Roosevelt (1882-1945). Al igual que Lincoln, Roosevelt fue acusado de actuar como un dictador cuando tomó la decisión de apoyar a Gran Bretaña en la guerra preocupado por la seguridad de los Estados Unidos. Roosevelt se presentó a una tercera reelección que ganó cómodamente debido a la crisis mundial y a la proyección de ser el dirigente adecuado para gestionar la política norteamericana en uno de los periodos más obscuros de su historia.

\section{LA ERA DE LA TELEVISIÓN: LA HUMANIZACIÓN DEL MITO DE RAÍCES DE GLORIA}

A partir del final de la Segunda Guerra Mundial y el inicio de la Guerra Fría hubo un decrecimiento en la imagen audiovisual de Lincoln debido al giro determinado por los movimientos que reivindicaban derechos civiles y que hizo que su figura entrara en crisis en un momento de profundas transformaciones sociales, poniendo en entredicho los preceptos sobre los que se articulaba su legado (Stokes, 2077: 221). También hubo un cambio en la recepción de la figura presidencial, que se renovó y modernizó con la irrupción y el gobierno de John Fitzgerald Kennedy (1917-1963) en el que no solo tuvo que ver el cambio político sino también la transformación mediática que convirtió la escena política en una parte determinante de la esfera comunicativa de la época y que coincidió con el declive del cine y el auge de la televisión.

Lincoln, por otra parte, seguía siendo un referente político. Con motivo de su 150 aniversario, el 12 de febrero de 1959, Dwight Eisenhower (1890-1969) creó el "Lincoln Sesquicentennial Commission" para celebrar los logros del presidente para la democracia, aunque la trascendencia de los actos estuvo muy alejada de la significación que había tenido

1 "Que no soy miembro de ninguna Iglesia Cristiana, es cierto; pero nunca he negado la verdad de las Escrituras. Es cierto que antes estaba inclinado a creer en lo que yo denominaba «la doctrina de la Necesidad»-que es que la mente humana está impulsada a la acción o la clama por algún poder [...] Lo he dejado hace cinco años y añado aquí [...] que siempre he creído que muchos de los credos cristianos compartían esa opinión”. Carta a los votantes del Séptimo Distrito para el Congreso publicada en el Illinois Gazette el 31 de julio de 1846 en respuesta a la acusación de que se burlaba de la religión (Guardia Herrero, 2008: 34 y Lincoln, 2015: 36). 
el Lincoln Memorial. La imagen del presidente entraría en crisis ya que se puso en duda su legado en lo referente a la esclavitud. De hecho, la inscripción de la escultura de Chester French reza: "En este templo/ como en los corazones de la gente/ por quién salvo la Unión/ la memoria de Abraham Lincoln/ se consagra para siempre”. La referencia a la Unión y no a la igualdad hizo que se recuperaran algunos de los discursos con Douglas en los que trazaba una división intelectual entre los blancos y las personas de color.

Pese a que hubo algunas películas destacables sobre su figura, aportan más bien poco a la construcción de su figura reinterpretando y perpetuando los arquetipos de los modelos cinematográficos previos. Por ejemplo, The Face of Lincoln (Edward Freed, 1955) era un cortometraje documental en el que el escultor Robert Martell Cage (1982-1981) realizaba un busto de Lincoln mientras explicaba los acontecimientos determinantes de su vida. The Lincoln Conspiracy (James L. Conway, 1977), basada en un libro homónimo de David W. Balsiger y Charles F. Sellier, mantenía la hipótesis de una conspiración para su asesinato en el que estarían implicados Edwin Stanton, el coronel Lafayette y senadores y políticos de la Unión que se oponían a la reconstrucción que proponía el presidente.

La pequeña pantalla explorará la figura y el legado de Lincoln en un periodo en el que su representación cinematográfica había perdido la intensidad de antaño. El cambio de formato permitiría desarrollar un mayor número de matices determinados por la segmentación episódica de la televisión y prácticamente todas las series se basaron en éxitos literarios. En el periodo de la era dorada de la televisión, Benjamin Chaplin dirigió para la CBS Abraham Lincoln: The early years (1952), una serie de cinco episodios de media hora de duración para la CBS y, en cuanto a películas para el medio destaca Abe Lincoln in Illinois (George Schaefer, 1964) que actualizaba la versión de Cromwell y Sherwood con Jason Robards en el papel protagonista.

En los años setenta, Lincoln se convirtió en un motivo referencial y, como ha señalado Mark S. Reinhard, existen más de 90 filmaciones sobre su figura en series, documentales, episodios de televisión y cortometrajes educativos ente 1970 y 1976. A este respecto encontramos la primera de las grandes series sobre el decimosexto presidente: Sandburgs Lincoln (1974-76) basada en la citada obra de Carl Sandburg que canonizaba su figura (Scott, 2011: 167) y realizaba una lectura acrítica y sin fisuras de la figura presidencial. El rol de Hal Holbrook como Lincoln convirtió al actor en un icono que reinterpretaría al presidente en la serie de ABC North and South (Norte y Sur, Kevin Connor, 1985) y al político Francis Preston Blair en la película de Spielberg.

En ese periodo hubo que desacralizar el legado del presidente replanteando modelos omitidos en su relectura hegemónica. En este sentido hubo aproximaciones críticas a su figura como Raices de gloria, (Lincoln, Lamont Johnson, 1988) -también intitulada como Gore Vidal's Lincoln - rodada para la pequeña pantalla en formato de miniserie para NBC que contó con un generoso presupuesto de ocho millones de dólares y se publicitó como el Lincoln que no se había visto nunca en pantalla (Snee, 2016: 123). Emitida en Estados Unidos el 27 y 28 de marzo de 1988, adaptaba la monumental obra homónima de Gore Vidal (1925-2012) publicada en 1984, uno de sus trabajos más ambiciosos de las denominadas «narrativas del Imperio» que intentaban reconstruir de manera crítica la historia de los Estados Unidos. El Lincoln de Vidal se inscribía en la escasa serie de los controvertidos anti-Lincoln (Snee, 2016: 128-129) proponiendo una visión heterodoxa de su presidencia que subrayaba la tibieza con la esclavitud y su utilización como recurso para preservar la Unión. Sobre el rigor histórico, Vidal mantenía que "todos los personajes principales han existido realmente, y han dicho y hecho en gran medida lo que yo les hago decir o hacer [...] en cuanto a Lincoln y a las demás figuras históricas, los he reconstruido a partir de cartas, periódicos, diarios, etcétera" (Vidal, 2013: 1008). Buscando la mayor verosimilitud histórica el último manuscrito del libro fue corregido por el profesor de Historia de Harvard, David Herbert Donald (1920-2009) que había dedicado la mayoría de sus estudios académicos a la figura de Lincoln y al Sur de los Estados Unidos.

Grabada en Richmond, Virginia, la serie reflejaba un espíritu similar al de la novela, con la dificultad de que se trataba de una adaptación de un texto de más de mil páginas en la que convergían varias tramas y decenas de personajes. Centrada en la cronología presidencial desde los días previos a tomar posesión el 4 de marzo de 1861, hasta su asesinato, el 14 de abril de 1865, Abraham Lincoln [Sam Waterson] llegaba de incógnito a Washington cuando seis 
de los Estados del Sur -denominados repúblicas del algodón- habían abandonado la Unión. El argumento se centraba en la política de Lincoln para mantener la Unión, la Guerra de Secesión, la nominación presidencial y las elecciones de 1864.

La filmación hacía constantes referencias a la política norteamericana. Vidal, incidía en la novela -y en sus ensayos políticos- que la presidencia de Lincoln aniquiló la República y convirtió a los Estados Unidos en un Imperio. De hecho, una de las propuestas que esgrimía el Secretario de Estado William H. Seward [Richard Mulligam], consciente del daño que la secesión provocaría en la proyección internacional del país es que los Estados Unidos invadieran Méjico, Centroamérica y Canadá para aunar la nación bajo el orgullo del expansionismo -la Confederación, por su parte, quería expandirse hacia el sur (Cuba) y hacia el oeste- por lo que la guerra era "un conflicto entre imperios rivales y no solo entre nacionalismos en competencia" (De Francisco \& Blackburn, 2013: 27).

Por otra parte, la serie desarrollaba uno de los puntos más controvertidos de la novela que mantenía que el presidente no era realmente un abolicionista: "el propio Lincoln insistía en 1861 en que el norte luchaba por defender la Unión, no por liberar a los esclavos" (Blackburn, 2013: 16) -de hecho, tenía familiares que poseían esclavos en el Sur- y utilizó la esclavitud con fines políticos. En su discurso de toma de posesión del 4 de marzo de 1861 expuso: "No tengo el propósito, ni directa ni indirectamente, de oponerme a la institución de la esclavitud en los Estados donde existe. Creo que no tengo derecho legal para hacerlo, ni me siento inclinado a ello" (Lincoln, 1996: 57). Como escribía Vidal: "liberó a todos los esclavos de los Estados que se habían revelado, pero mantuvo la esclavitud en los Estados fronterizos que habían permanecido leales a la Unión. El mundo no lo aceptó, si bien Lincoln sabía lo que se hacía: primero la Unión y luego abolición" (Vidal, 2007: 707) que refrendaba el discurso de Lincoln sobre el axioma que, desde la legalidad, la Unión era perpetua. Para Lincoln los afroamericanos nunca alcanzarían la igualdad con los blancos y no dejó de verlos como extraños que debían abandonar los Estados Unidos. En el discurso con Douglas el 18 de septiembre de 1858 afirmaría: "no estoy, y nunca he estado, en favor de convertir a los negros en votantes o jurados, ni de autorizarlos a ocupar cargos ni a casarse con gente blanca" (Blackburn, 2013: 42). La idea de que la guerra no tuvo que ver con la cuestión de la esclavitud y sí con una posición hegemónica en la escena mundial la señalaría igualmente Marx en 1861 (2013: 135). Por lo tanto, la solución al problema racial que proponía Lincoln sería compensar a los dueños de los esclavos y aplicar la teoría de Henry Clay (1777-1852), es decir, ofrecer la posibilidad a los afroamericanos con formación y a los esclavos la colonización de Nueva Granada en Centroamérica.

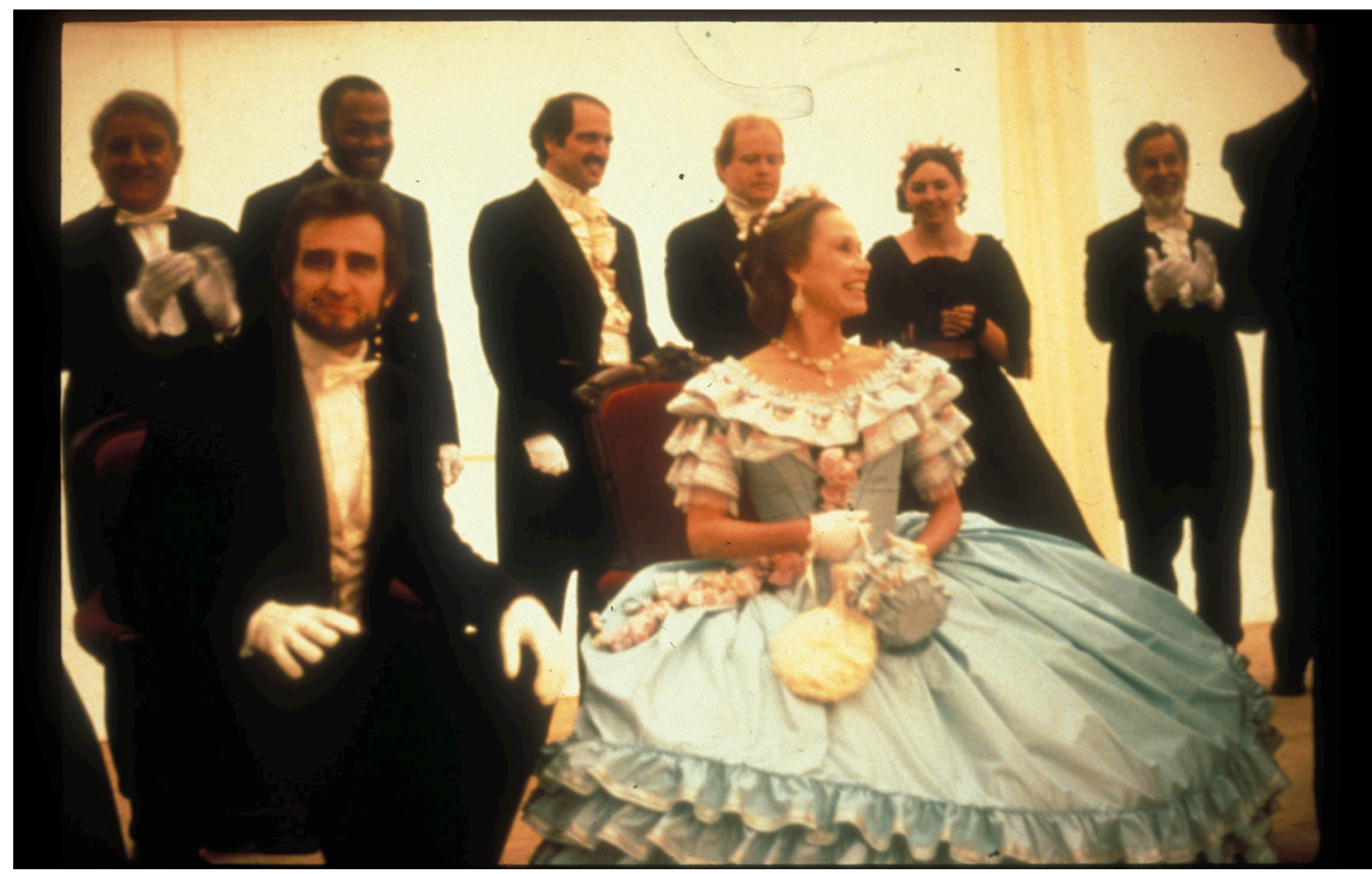

Figura 7. Lincoln [Sam Waterson] y Mary Todd [Mary Tyler Moore] en Raíces de Gloria, Lamont Johnson. 1988. 
Centrada en el ámbito político y sus intrigas -la mayoría de la filmación se sucede en interiores- recreaba las reuniones y la vida íntima de Lincoln, narrando fidedignamente las diversas crisis a las que se vio sometido su ejecutivo: la presión de los abolicionistas radicales, las conjuras por el poder en el partido republicano, los conflictos militares y la inoperancia de los generales de la Unión -incluido Ulysses S. Grant- las derrotas, la posibilidad de que Maryland se pasara al bando sudista, además de la amenaza real de que los confederados tomaran Washington.

El contrapunto a la trama política lo constituye la vida familiar de Lincoln. Pese a que la novela, evidentemente, ofrecía una gama mayor de matices, la adaptación televisiva focalizaba el protagonismo en Mary Todd Lincoln [Mary Tyler Moore] que, a partir de su llegada a la Casa Blanca, ejerce de facto como primera dama decorando la vieja casona que siente abandonada para la que hace costosas compras sin fondos. Esto, a la postre, la convertiría en víctima de los acreedores de Washington y Nueva York y motivaría futuros problemas políticos asociados a la venta de favores. La constante búsqueda de fuentes de financiación se convertiría en un inconveniente para Abraham Lincoln que tendría que hacer frente a los desvaríos de su mujer. Lincoln aceptaba con resignación los problemas que le provocaba su esposa debido a los reveses de su vida familiar sabiendo que su mujer tenía serios problemas mentales -de hecho, su hijo Robert T. Lincoln (1843-1926) tuvo que ingresarla en un psiquiátrico en 1875-. La serie mostraba hechos que no había señalado ninguna película anterior. Probablemente, el Abraham Lincoln que reconstruye Raíces de gloria sea la más humana de las representaciones del presidente, en la que se describía a un hombre angustiado y a la vez a un político soberbio: "frío y calculador, reflexivo, brillante [...] sabía cuándo esperar y cuándo actuar" (Vidal, 2007: 705-8). La serie, por otra parte, reconocía el convencimiento fatalista de un hombre que estaba cumpliendo una misión histórica y comprendía, de antemano, que no sobrevivirá una vez hubiera concluido su tarea, además de incidir en la invención de su propia dimensión política y a las relecturas y proyección en el futuro a partir de su deceso (Snee, 2016: 131).

\section{LOS ÚLTIMOS AÑOS. DE LA CRÍTICA A UN NUEVO MODELO CANÓNICO}

En cuanto a las últimas revisiones cinematográficas sobre la figura del decimosexto presidente es necesario citar La conspiración (The Conspirator, Robert Redford, 2011) que retomaba el argumento de Prisioneros del odio. Producida por The American Film Company, reconstruía la historia del asesinato de Lincoln el 14 de abril de 1865 y el controvertido juicio que tuvo Mary Surratt (1820-1865). La historia se iniciaba con el asesinato del presidente y el ataque al Secretario de Estado William H. Seward. A partir de ahí, Redford (1936) trazaba una historia en la que se ponía en tela de juicio un sistema judicial que infringió sistemáticamente los derechos constitucionales. La conspiración seguía la estela de la crítica al sistema de otras películas de Redford como Quiz Show: El dilema (Quiz Show, 1994) y Leones por corderos (Lions for Lambs, 2007), estableciendo paralelismos entre el hecho histórico y la política de refuerzo de la seguridad nacional de la administración Reagan que se endureció con la Ley Patriótica de la Bush-Cheney. Su estreno en Estados Unidos el 15 de abril de 2011, coincidió con el aniversario de la muerte de Lincoln y con la decisión de Obama de no cerrar Guantánamo, incumpliendo una de sus promesas de su programa electoral. El filme hacía una reflexión sobre la vulneración de las libertades civiles -la presunción de inocencia y el derecho a un juicio justo- dañadas por las medidas de seguridad especiales (Sánchez Escalonilla \& Rodríguez Mateos, 2014: 275).

Tras más de siete décadas sin una película relevante sobre su figura, Steven Spielberg (1946) se embarcó en Lincoln (2012), una epopeya histórica cuyo núcleo argumental se concentraba en la aprobación de la Decimotercera Enmienda de la Constitución que aboliría la esclavitud en los Estados Unidos. Por otra parte, constituía una nueva aproximación al problema racial que el director había abordado en El color púrpura (The Color Purple, 1985) -basado en la novela homónima de la escritora afroamericana Alice Walker (1944)- y Amistad (1997). En Amistad, el expresidente y abogado John Quincy Adams (1767-1848) [Anthony Hopkins] esgrimía una premonitoria frase sobre que la última revolución americana estaría determinada por la emancipación de los afroamericanos en los Estados Unidos, aunque fuera a costa de una guerra civil.

El guion de Tony Kushner (2011) estaba basado en Team of Rivals: The Political Genius of Abraham Lincoln (2005) de la historiadora Doris Kearns Goodwin (1943). El director adquirió 
los derechos del libro de Kearns antes de que ésta concluyera el libro y la historiadora participó en el proceso de la película. Spielberg reconocía que el resultado era fiel al contenido del libro y quería redescubrir al político y al ser humano en un filme que pretendía ser una lección de pedagogía histórica. El protagonista recayó en Daniel Day Lewis, una imposición del director sin el que no hubiera desarrollado el proyecto, ya que deseaba tener al mejor actor para representar al mejor presidente. El actor se sintió intimidado por su rol, reconociendo, tras el rodaje, que el esfuerzo interpretativo fue de tal magnitud que envejeció durante su interpretación, e incluso, que sintió tristeza cuando finalizó la misma (Díaz-Cuesta, 2013: 655).

La película se localizaba entre enero y abril de 1865 cuando Lincoln afrontaba su segundo mandato y el conflicto bélico con el Sur había entrado en su cuarto año. En ese periodo, el presidente centró sus energías en la aprobación la decimotercera enmienda para lo que utilizó todos los medios, legales e ilegales -la compra de los votos de los diputados demócratas no electos con la promesa de trabajos públicos, por ejemplo- para ganar una votación que no tenía posibilidad de prosperar. Por tanto, la idea principal de Lincoln era salvar la Unión, pero dejando aprobada la enmienda para abolir la esclavitud.

Lincoln comenzaba con una declaración de intereses que anticipará su discurso futuro. Tras una batalla entre soldados de color de la Unión y los confederados - una cita a Tiempos de gloria (Glory, Edward Zwick, 1989)² - uno de los regulares afroamericanos señalaba al presidente la importancia de su función en el ejército pese a la inferioridad con sus homólogos blancos: "quizá en unos años toleren la idea de tenientes y capitanes negros, en cincuenta años quizá un coronel negro, en cien años el voto". Esta referencia tenía una doble misión: por una parte, recrear verosímilmente el hecho de la participación de los soldados de color " 180.000 afroamericanos en el ejército de la unión y 20.000 en la marina -para el final del conflicto, algo más de un centenar de afroamericanos habían sido nombrados oficiales de las unidades de color-" (Blackburn, 2013: 39) y por otra, conectaba con el periodo histórico en el que se realiza la filmación, en el que había un inquilino afroamericano en la Casa Blanca: Barack Obama.

Con la guerra de fondo, Lincoln volcaría toda su energía en la aprobación de la enmienda. Llevar a cabo ese proyecto era complicado por la presión de las diversas facciones políticas. De hecho, la urgencia de su aprobación era acuciante para terminar una guerra que estaba desangrando al país, en un momento, como le recuerdan sus asesores, en el que solo podría ganar la enmienda o la guerra, pero no ambas. A partir de ahí, Spielberg reconstruiría cómo el presidente desplegaba toda su inteligencia y su capacidad de persuasión para lograr sacar adelante su propuesta acallando las críticas, las ambiciones e intereses velados de los radicales de ambos bandos.

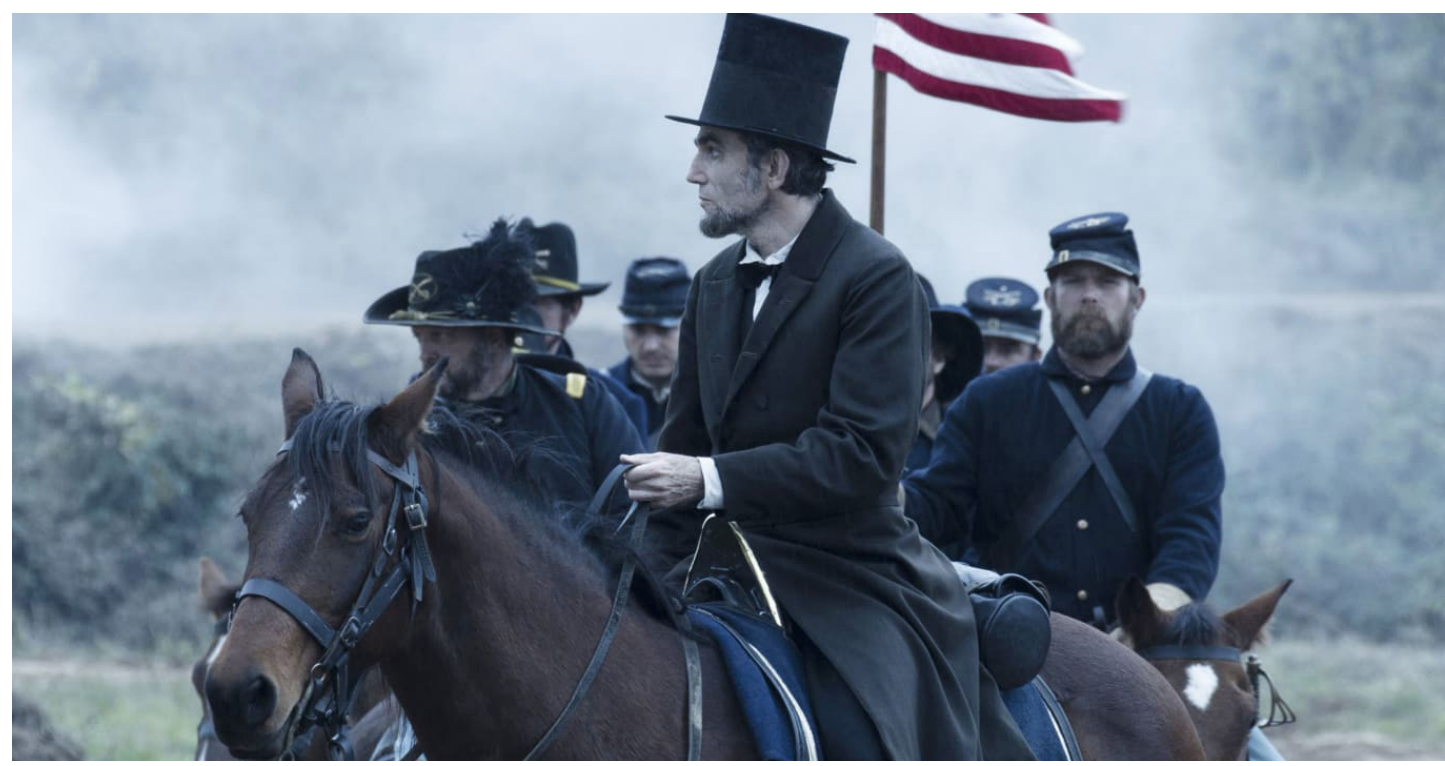

Figura 8. Abraham Lincoln [Daniel Day-Lewis] en Lincoln, Steven Spielberg. 2012.

2 Centrado en un episodio histórico concreto "la acción bélica del 54 de Massachusetts, el primer regimiento compuesto íntegramente por voluntarios afroamericanos al mando de un oficial blanco, coronel Robert Gould Shaw, que fueron masacrados en la segunda batalla de Ford Wagner, el 18 de julio de 1863” (Caparrós Lera, 2009: 198). 
La tensión dramática se concentraba en el día de la votación. De hecho, la filmación estaba concebida para construir este momento decisivo de la historia norteamericana. Previamente, se acentuaba la simbología en el momento que en las tribunas aparecían personas de color en el congreso. Los congresistas iban otorgando su voto y algunos de los que tenían claro -o que no habían dejado disuadirse por las promesas de Lincoln- variarían su elección. Una vez que la enmienda salió adelante Thaddeus Stevens [Tommy Lee Jones] sintetizaría el mensaje y la dimensión histórica de los hechos reseñados: "The greatest measure of the Nineteenth Century. Passed by corruption, aided and abetted by the purest man in America”. (La ley más importante de la historia de los Estados Unidos se ha aprobado mediante un proceso corrupto manejado por el hombre más puro y honrado que ha dado América). (Kushner, 2011, 114).

Con una puesta en escena clásica y contenida -que en cierto modo traicionaba el estilo del director- el desarrollo de la película estaba articulado sobre la densidad verbal que la hace avanzar. Hay escasas incursiones en la acción, exceptuando la escena de la batalla inicial, con lo que la película se convierte en una extensión de la palabra como símbolo del líder que transformaría los tiempos pensando en el futuro: "Lincoln ha de ser capaz de gestionar su propio tiempo y los tiempos de sus contrincantes: con su gesto, parece que estuviera controlando ese tiempo, pero en realidad lo que hace es adaptar su mente al devenir de la Historia” (Díaz-Cuesta, 2013: 664).

La propuesta de Spielberg tenía bastantes puntos comunes con la miniserie de Lamont Jonhson. La verosimilitud histórica a través de una novela y el apoyo de especialistas en la materia; la estructura narrativa basada en el diálogo como eje constituyente de la acción; el control escénico limitado localizado en interiores en el que la iluminación de Janusz Kaminski rozaba en muchos casos el tenebrismo; las localizaciones exteriores en Virginia; la dualidad de la propuesta que no solo era política sino humana, en la que se representaban las tensiones familiares, las disputas con su hijo y con Mary Todd -aunque en este caso sin profundizar en su enfermedad- y a la reproducción de los sueños premonitorios del presidente citados en la obra previa de Vidal y Johnson como proemio a la catástrofe personal y al triunfo histórico que enfatizaba el sacrificio personal a favor de una causa colectiva.

Spielberg hacía referencia al legado político del presidente, aunque el director elaboraría el discurso en torno a una figura convencida de su misión que puso los cimientos para resolver el problema racial en los Estados Unidos o, al menos, focalizaba su problemática en el pasado para retrotraerla a la actualidad.

Pero Lincoln no era solo historia, sino que quería ser también memoria y rememoración del pasado. Spielberg manifestó que estaba fascinado por la figura del presidente y, como habían reconocido David Griffith o John Ford, era algo que resultaba fundamental para plantear una versión cinematográfica. Como muchos norteamericanos, Spielberg visitó el Lincoln Memorial cuando era un niño y le impresionó la monumental figura representada, pero más que intimidarle le pareció una figura protectora. Por ello focalizaba la relevancia histórica de Lincoln en el pasado para comprender el presente y, en cierto modo, señalar el futuro. La presidencia de Lincoln, según Spielberg, proporcionó un sentido de liderazgo articulando la idea del gobierno como algo positivo para el pueblo a través de la educación y el respeto por las leyes, la tolerancia, la justicia y la compasión y, a la vez, citaba la destreza de Lincoln en un periodo de crisis de la administración Obama, que afrontaba momentos críticos por no cumplir sus compromisos electorales (Sánchez Escalonilla \& Rodríguez Mateos, 2014: 281).

Evidentemente la magnitud de la propuesta de Spielberg -con más de 300 millones de dólares de taquilla- ensombreció las últimas propuestas cinematográficas de Lincoln como Killing Lincon (Matar a Lincoln, Adrian Moat, 2011), filme para televisión basado en el libro homónimo Bill O’Reilly y Martin Dugard rodado a partir de documentos de archivo y elementos de ficción, películas que focalizaban al presidente a partir de las personas que lo rodeaban como Saving Lincoln (Salvador Litvak, 2013) que narraba la historia del alguacil Ward Hill Lamont su guardaespaldas durante su presidencia o The Better Angels (2014), dirigida por A. J. Edwards y producida por Terrence Malick, focalizada en la infancia de Lincoln en Indiana y la relación con su madre y su hermana. 


\section{CONCLUSIONES}

Como señalan los historiadores Barry Schartz y Merrill D. Peterson, el recuerdo colectivo norteamericano del legado histórico y político de Abraham Lincoln estaría determinado por las películas (Stokes, 2007: 203). A través de las diferentes aproximaciones cinematográficas y televisivas hemos podido observar cómo su figura se ha utilizado adaptándose al contexto histórico en el que ha sido representada. Por lo tanto, más allá de una interpretación reduccionista, podemos considerar varias lecturas que elaboran un modelo de representación del decimosexto presidente. El personaje de Lincoln se transformaba en diferentes guías que ejemplificaban su legado y lo fomentaban en periodos críticos de la cronología norteamericana.

Las primeras referencias a Lincoln comenzaron en los albores del cinematógrafo ya que apenas habían pasado tres décadas desde su magnicidio y su recuerdo y legado estaban muy presentes en el imaginario norteamericano. El cine, como espejo de la época, ofrecía una visión fragmentada de su figura incidiendo en su disposición para el diálogo, el restablecimiento de la paz y la creación de las condiciones para una unidad sin recelos y fisuras.

La representación de su figura se hizo más densa y compleja a través del protagonismo que adquiriría en la primera mitad de El nacimiento de una nación, focalizada en las heridas abiertas de la Guerra de Secesión. La visión de Griffith reivindicaba la defensa de Lincoln de los derechos de los antiguos confederados, así como el carácter conciliador de su política en un periodo de reconstrucción de la mitología estadounidense determinada por el problema racial en un periodo en el que los Estados Unidos estaban a punto de entrar en la Primera Guerra Mundial.

En los años de la Depresión y de la Segunda Guerra Mundial, el cine dirigió su mirada al presidente a través de una lectura monolítica que ejemplificaba la superioridad de los ideales norteamericanos en contraste con la descomposición del viejo mundo, y de un legado que lo reivindicaba como el primer norteamericano. El arquetipo representacional, en este caso, coincidía con el espíritu de audacia y sacrificio que se les presupone a todos los estadounidenses en la defensa de unos ideales que habían sido agredidos y con el que Lincoln se convierte en el referente fundamental. En el caso concreto de la película de John Ford, no solo se trataba de la figura que Abraham Lincoln había sido, sino de la que llegaría a ser, realizando paralelismos entre su personalidad y su legado relacionado con el norteamericano común. Ese espíritu señalado en las filmaciones de Griffith y Cromwell determinaba la estela estética y conceptual que aparecerá en otras aproximaciones cinematográficas.

La crítica al sistema a partir del último cuarto del siglo pasado nos envía a un modelo que, lejos de la sacralización, se construye con rasgos marcadamente humanos, en el que encontramos a un fatalista con crisis personales y familiares. En el terreno político, se le representaba como un personaje obligado a cumplir la misión histórica que se le había encomendado y para la que se arrogó los poderes de un dictador con el fundamento de mantener la Unión y en el que la esclavitud fue un tema subsidiario de la salvaguarda patria. El descrédito de las diferentes administraciones, el recorte de las libertades individuales y la vulneración de los derechos constitucionales se ha permeabilizado en las lecturas cinematográficas contemporáneas en las que el legado de Abraham Lincoln ha servido de recuerdo y referencia ante la deriva incierta y las políticas erráticas de las administraciones norteamericanas cerrando filas en torno a su figura, de nuevo, cuando el país se ha sentido amenazado externamente. 


\section{REFERENCIAS BIBLIOGRÁFICAS}

- Álvarez Junco, J. (2017). Dioses útiles. Naciones y nacionalismos. Barcelona: Galaxia Gutenberg.

- Benbow, M. E. (2010). Birth of a Quotation: Woodrow Wilson and "Like Writing History with Lightning. The Journal of the Giled Age and Progressive Era, 9 (4), 509-533. https:// www.jstor.org/stable/20799409 [Consultado el 1 de mayo de 2021].

- Caparrós Lera, J. M. (2009). La guerra civil americana vista por el cine. Palabra clave Vol. 12, número 2, diciembre de 2009, 195-206. https://palabraclave.unisabana.edu.co/index. $\mathrm{php} /$ palabraclave/article/view/1560 [Consultado el 11 de mayo de 2021].

- Casas, Q., Losilla C. y Eisenstein, S. M. (2017). El joven Lincoln, Barcelona: La Aventura.

- De Francisco, A. y Blackburn, R. (2013). Guerra y emancipación. Lincoln \& Marx. Madrid: Capitán Swing.

- De la Guardia Herrero, C. (2008). Abraham Lincoln y la Unión de los Estados Unidos. En Flores Juberías C. (ed), Todos los hombres del presidente. La presidencia de los Estados Unidos vista a través del cine. Valencia: Quaderns del MuVim, 27-41.

- Díaz-Cuesta, J. (2013). El hombre y su representación en Lincoln (Steven Spielberg, 2012): un análisis textual. Historia y Comunicación Social, (18) N $\mathrm{N}^{\mathrm{O}}$ Esp, 653-666. https://doi. org/10.5209/rev_HICS.2013.v18.44356 [Consultado el 19 de abril de 2021].

- Fletcher, G. P. (2001). Our secret Constitution. How Lincoln Redefined American Democracy. Nueva York: Oxford University Press.

- Gallagher, T. (2009). John Ford. El hombre y su cine. Barcelona: Akal.

- Gimferrer, P. (2000). Cine y literatura. Barcelona: Seix Barral.

- Goyeneche-Gómez, E. (2012). Las relaciones entre cine, cultura e historia: una perspectiva de investigación audiovisual. Palabra clave 15 (3), 387-414. https://www.redalyc.org/articulo. oa? id=64924872003 [Consultado el 27 de abril de 2021].

- Gutiérrez Delgado, R. (2011) Young Mr. Lincoln (1939): El rastro de la historia en un mito de John Ford. Filmhistoria Online, 2 (21) http://revistes.ub.edu/index.php/filmhistoria/article/ view/13838 [Consultado el 26 de abril de 2021].

- Gutiérrez Delgado, R. (2011). Abe Lincoln, pasión y justicia en la ficción fordiana. Young Mr. Lincoln (1939): un perfil épico. En G. Camarero (Ed.), La biografía fílmica: actas del Segundo Congreso Internacional de Historia y Cine, (pp. 810-830) Madrid: T\&B. https://earchivo.uc3m.es/handle/10016/11376 [Consultado el 26 de abril de 2021].

- Kearns Goodwin, D. (2009). Team of Rivals. The Political Genius of Abraham Lincoln. Penguin: Nueva York.

- Kushner, T. (2011). Lincoln. Final Shooting Script, https://stephenfollows.com/resource-docs/ scripts/Lincoln-Screenplay.pdf [Consultado el 8 de mayo de 2021].

- Lincoln, A. (2015). Por la libertad. Barcelona: Plataforma.

- Lincoln, A. (1998). Discurso del 4 de marzo de 1861 en AA.VV. Discursos inaugurales. León: Universidad de León, 57-77.

- Lincoln, A. (2005). El Discurso de Gettysburg y otros escritos sobre la Unión. Madrid: Tecnos.

- Mariani, S. (2018). Salvar la Unión y abolir la esclavitud: Abraham Lincoln en su hora más gloriosa en M. Alcántara, S. Mariani, (Eds.), La politica es de cine. Madrid: (CEPC) Ministerio de la Presidencia, 181-198. https://www.academia.edu/35910953/Salvar_la_Unión_y_abolir_la esclavitud_Abraham_Lincoln_en_su_hora_más_gloriosa [Consultado el 21 de abril de 2021].

- Marzal, J. J. (1998). David Wark Griffith. Cátedra: Madrid.

- McBridge, J. (2004). Tras la pista de John Ford. T\&B: Madrid.

- Montero, I. (2004). Abraham Lincoln. Barcelona: Folio.

- Morettin, E. (2011)., O cinema e o mito da democracia americana: Abraham Lincoln e John Ford. Famecos: midia, cultura e tecnología, 18, (1), 11-22. https://doi.org/10.15448/19803729.2011.1.8794 [Consultado el 22 de abril de 2021].

- Reinhard, M. S., (2009). Abraham Lincoln on Screen: Fictional and Documentary Portrayals on Film and Television. McFarland: Jefferson/Londres.

- Rosenstone, Robert A. (1997). El pasado en imágenes. El desafío del cine a nuestra idea de la Historia. Ariel: Barcelona.

- O' Reilly, B. y Dugard, M. (2011). Matar a Lincoln. Madrid: La esfera de los libros. Edición Kindle. www.amazon.com.

- Paquet-Deyris, A. M. (2016). Form "Plain Abe" to Mythical Mr. Lincoln. Constructing varius 
representational modes of a screen icon, IdeAs [Online], $7 \mathrm{https} / /$ doi.org/10.4000/ideas. 1424 [Consultado el 20 de abril de 2021].

- Reinhard, M. S. (2009). Abraham Lincoln on Screen: Fictional and Documentary Portrayals on Film and Television. McFarland: Jefferson/Londres.

- Sánchez-Escalonilla, A. Rodríguez Mateos, A., (2014). La recuperación fílmica de la figura presidencial norteamericana en un contexto de crisis: Hollywood durante los mandatos de Barack Obama (2009-2014) Fotocinema, 8, 255-283. https://doi.org/10.24310/Fotocinema.2014. v0i8.5953 [Consultado el 29 de abril de 2021].

- Scott, I. (2011). American Politics in Hollywood Film. Edimburgo: Edinburgh University Press.

- Snee, B. J. (2016). Lincoln before Lincoln: Early Cinematic Adaptations of the Life of America's Greatest President. University Press of Kentucky: Lexinton.

- Stokes, M. (2007). D. W. Griffith's The Birth of a Nation. A History of "The Most Controversial Picture of All Time. Oxford: Nueva York. https://www.academia.edu/18422918/_Melvyn_ Stokes_D_W._Griffith_s_The_Birth_of_a_Nat_Book_Fi_org_ [Consultado el 15 de abril de 2021]. - Stokes, M. (2011). Abraham Lincoln and the Movies. American Ninetheeth Century History, 12, (2) pp. 203-231.

- Vidal, G. (2013). Lincoln. Barcelona: Edhasa.

- Vidal, G. (2007). Ensayos (1952-2001). Barcelona: Edhasa. 